\title{
A Comparative Study on Fuel Consumption Reduction Effects of Eco-Driving Instructions Strategies
}

\author{
Shuichi Matsumoto • Taehwi Park • Hironao Kawashima
}

Received: 29 March 2012 /Revised: 21 June 2013 / Accepted: 31 July 2013 / Published online: 12 October 2013

(C) The Author(s) 2013. This article is published with open access at Springerlink.com

\begin{abstract}
Eco-driving is expected to contribute to the efforts to fight against global warming by reducing carbon dioxide emissions from vehicles. It is the driving technique that enables low fuel consumption mainly by accelerating gently at the start and avoiding frequent accelerating and decelerating. The effectiveness of eco-driving has been assessed based on a single vehicle; however, it remains to be investigated on multiple vehicles. This paper assesses the effects of eco-driving when following other vehicles on open roads under two different instructions (Japanese eco-driving and German eco-driving) to reduce fuel consumption based on the experiment environment by integrating a driving simulator and a traffic simulator.
\end{abstract}

Keywords ITS · Traffic flow · Global environmental problems

\section{Introduction}

The Kyoto Protocol, adopted in 1997, required Japan to reduce its greenhouse gas emissions over the period from 2008 to 2012 to $6 \%$ below the level in 1990. In addition, in June 2009, Japan announced a mid-long term target to reduce its greenhouse gas emissions by $25 \%$ from the 1990 levels by 2020. The breakdown of carbon dioxide emissions in Japan

S. Matsumoto $(\bowtie)$

Faculty of Science and Technology, Keio University, 3-14-1 Hiyoshi, Kohoku-ku, Yokohama 223-8522, Japan

e-mail: shuichi@ae.keio.ac.jp

T. Park

Faculty of Medicine, Asahikawa Medical University, 1-1-1

Midorigaokahigashinijo, Asahikawa 078-8510, Japan

H. Kawashima

Co-Mobility Society Research Center, Keio University, 7-1

Shinkawasaki, Saiwai-ku, Kawasaki 212-00322, Japan indicates that the emissions from transportation account for $20 \%$ of the total, and it is mostly from vehicles. In such situations, eco-driving is attracting attention as one of the ways to reduce carbon dioxide emitted by vehicles.

Eco-driving is considered to be effective in improving the fuel efficiency and is being promoted in various ways. One of the representative activities in Japan is " 10 tips for fuelconserving Eco-Driving" promoted by Team Minus $6 \%$ [1]. "10 tips for fuel-conserving Eco Driving" recommends drivers techniques such as a soft starting with gentle acceleration, called "e-start", and driving without excessive accelerating and decelerating. In this paper, such driving techniques are collectively referred to as Japanese eco-driving. On the other hand, in Europe especially in Germany, the driving technique to accelerate quickly to reach the fuel efficient range as fast as possible, which differs from Japanese eco-driving, is being widely implemented as eco-driving [2]. This driving technique is called German eco-driving. The biggest difference between Japanese and German eco-driving is how to accelerate when the vehicle starts moving. This study aims to evaluate quantitatively the difference in the fuel consumption rates during driving between Japanese ecodriving and German eco-driving.

\section{Position of this Study}

The effect of Japanese eco-driving in reducing fuel consumption rates has been verified in various actual driving situations, including the comparison of before and after education for transport drivers such as truck drivers [3, 4] and the comparison of before and after instruction of eco-driving for general drivers [5]. However, there have been few studies of comparison performed in the same conditions.

With regard to German eco-driving, Beusen et al. [6] reported that the fuel consumption was improved after a driver 
Fig. 1 General picture of driving simulator

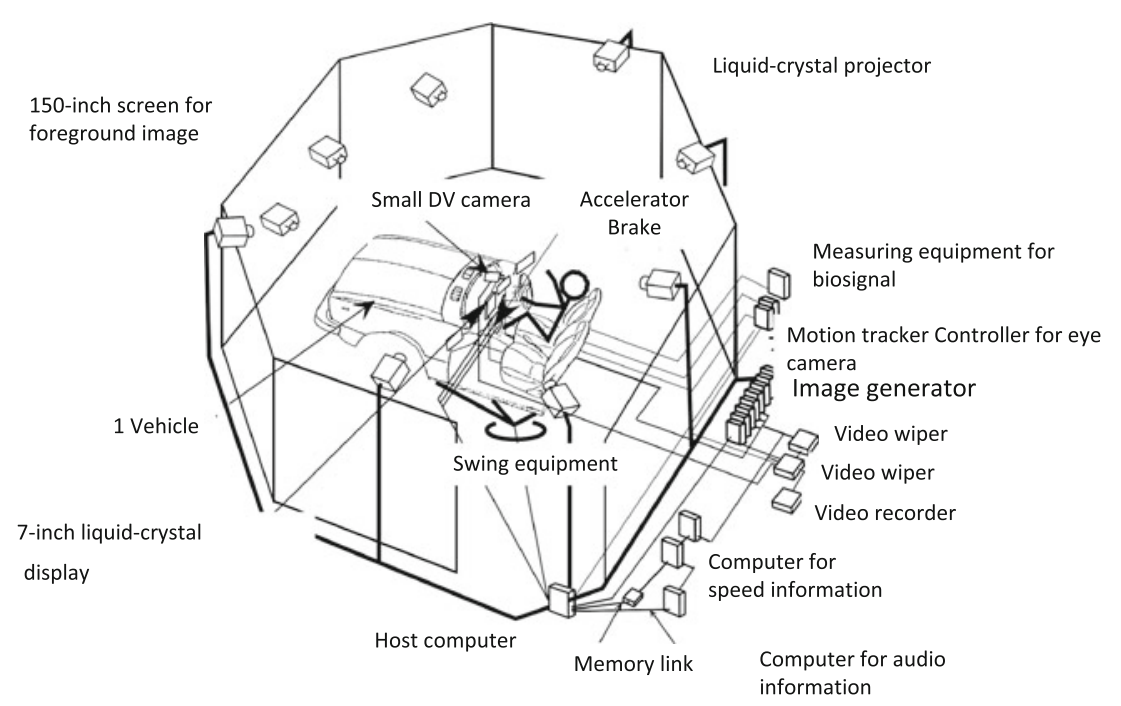

education course on eco-driving was given compared to that of before, through obtaining the driving data of 8 subjects.

As a comparative study on the effects of Japanese ecodriving and German eco-driving, the author et al. [7] analyzed the differences of the effects between Japanese eco-driving and German eco-driving on the fuel consumption rates based on the data of actual vehicle experiments. In this study, the fuel consumption rates were estimated based on the distributions of velocity-acceleration in normal driving, driving with Japanese eco-driving and with German eco-driving. In addition, Kato et al. [8] held an eco-driving test-ride event with actual vehicles to compare the difference between eco-driving while paying attention to gentle acceleration (equivalent to Japanese eco-driving in this paper) and while paying attention to speedier acceleration (equivalent to the German eco-driving in this paper), which proved that both techniques of eco-driving improved the fuel efficiency compared to normal driving.

As a study using a driving simulator (hereafter called "DS"), we can look at the study by Hiraoka et al. [9]. In this study, an experiment was conducted with the condition to drive following the preceding vehicle in JC-08 mode. It concluded that German eco-driving improves fuel efficiency more than Japanese eco-driving does when compared to normal driving. Furthermore, to conduct an empirical study on open roads with traffic lights is cited as a future challenge.

Therefore, this study analyzed while focusing on the vehicle behavior between two intersections with traffic lights, and compared Japanese eco-driving and German eco-driving about the effect to improve fuel efficiency and the driving behaviors over short distances on open roads in DS, which has been rarely discussed in detail until now.

\section{Experimental Overview}

\subsection{Experiment Environment}

In this study, an experiment was performed under an environment with simulated intersections in a virtual space, created by integrating a DS by Keio University and a traffic simulator "AIMSUN" [10] (hereafter called "TS") (hereafter called "TS/ DS integration"). The DS was jointly developed by Keio University and the National Institute for Land and Infrastructure Management [11], and is made by MITSUBISHI PRECISION CO., LTD. The TS is made by TSS-Transport Simulation Systems, S.L.(TSS).

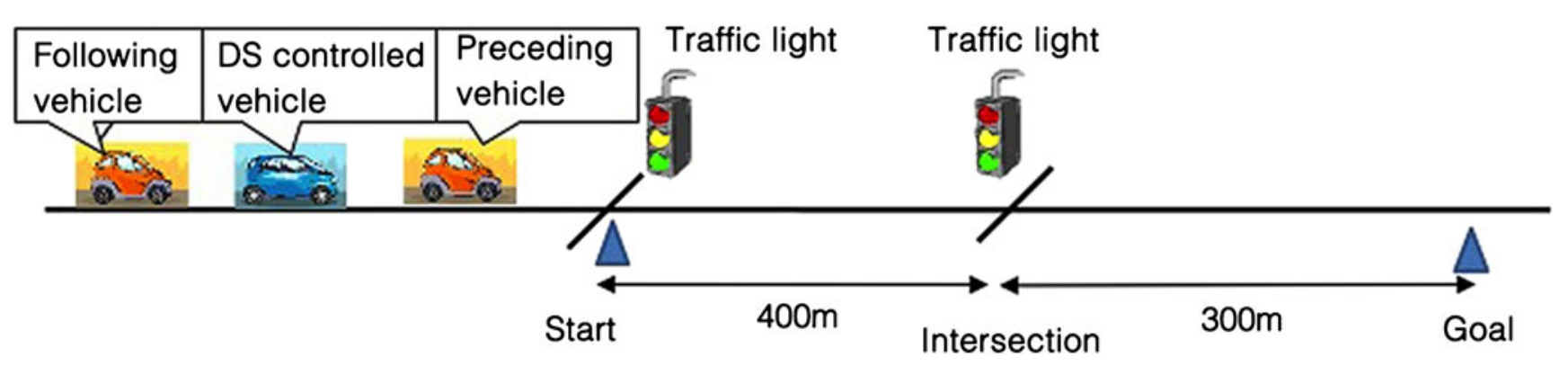

Fig. 2 Summary of experiment scenario 
Our study group has performed computer experiments using a TS in the study into the effects of signal control and street parking on smooth traffic flow [12] and in the review and evaluation of public transportation operational procedures [13]. And the study also used a DS in our experiments into the effects of information provision in consideration of human factors of drivers $[14,15]$. Experiments with a TS have the advantage that we can evaluate traffic flow through a vehicle group, using a following model of generalized vehicles. On the other hand, experiments with a DS have the advantage that vehicle control data can be quantified based on each driver's driving characteristics. Incorporating these advantages of TS and DS, we created the TS/DS integration to quantify the driving action in a heavy traffic situation or under complicated signal control. This TS/DS integration is for conducting the driving experiment using a DS in the experimental scenario which is developed through use of a TS. In addition, the data output of travel time, delayed time, stopping time and average velocity can be obtained from the TS, and that of acceleration, velocity, engine speed, accelerator pedal input, brake pedal input and the position of the vehicle can be obtained from the DS.

The DS used in this study is composed of eight image screens, front, left and right fronts, left and right sides, left and right rear, and backside (Refer to Fig. 1). A driving image from 10 projectors is projected to these screens. A 360-degree field of vision is provided to the driver in the driver seat. The left and right side mirrors and the rearview mirror are the same type as those for actual vehicles, and they capture indirectly the image on the reverse side of the screen. Furthermore, swing equipment with six axes is attached to the vehicle body. All the equipment is collectively controlled using the main calculator.

In this study, an experimental scenario of a straight open road was developed using a TS. The scenario begins with the situation where a vehicle stopped at a traffic light starts moving. It drives straight for $300 \mathrm{~m}$, then must stop at a signalized intersection, and drives straight for $300 \mathrm{~m}$. Each subject got into a DS controlled vehicle which had set that there were vehicles driving in front and at the back. (Refer to Fig. 2). The preceding and following vehicles ran according to the vehicle behavior model programmed in the TS [10], and their speed

Table 1 Main TS parameters

\begin{tabular}{ll}
\hline Item (unit) & Mean value (standard deviation) \\
\hline Maximum desired speed $(\mathrm{km} / \mathrm{h})$ & $50(0)$ \\
Maximum acceleration $\left(\mathrm{m} / \mathrm{s}^{2}\right)$ & $3.0(3.0)$ \\
Maximum speed $\left(\mathrm{m} / \mathrm{s}^{2}\right)$ & $6.0(0.5)$ \\
Minimum inter-vehicular distance (m) & $1.0(0.3)$ \\
\hline
\end{tabular}

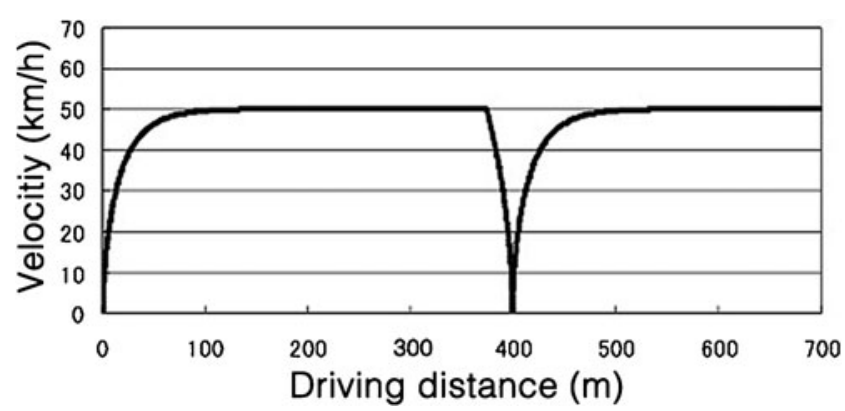

Fig. 3 Relationship between velocity and driving distance of preceding vehicle

limit was set at $50 \mathrm{~km} / \mathrm{h}$. The main TS parameters, which affect drivers of both preceding and following vehicles, were set as in Table 1. As the vehicular swept path of the preceding vehicle, the relation between velocity and distance is shown in Fig. 3.

\subsection{Calculation of Fuel Consumption}

In this study, the fuel consumption amount calculated based on the map shown in Fig. 4, which is in the same manner as the study by Hiraoka et al. [9]. This map is included in the vehicle motion simulation software, CarSim. It shows the instantaneous fuel consumption amount $(\mathrm{kg} / \mathrm{s})$ for engine speed and an operation amount on the accelerator of the ordinary motor vehicle with a 2.5-1 gasoline engine. We calculate the fuel consumption rate $\mathrm{km} / \mathrm{l}$ from this obtained amount, the standard density of gasoline $0.76 \mathrm{~kg} / \mathrm{l}$ and the vehicle velocity $\mathrm{km} / \mathrm{h}$.

Figure 4 shows that in the area with very low accelerator pedal input, the fuel consumption amount does not change remarkably even if the engine speed is increasing. When a vehicle is in a coasting state or a braking state, it is usually included in this area. In the area with high accelerator pedal input, the fuel consumption amount increases as the engine

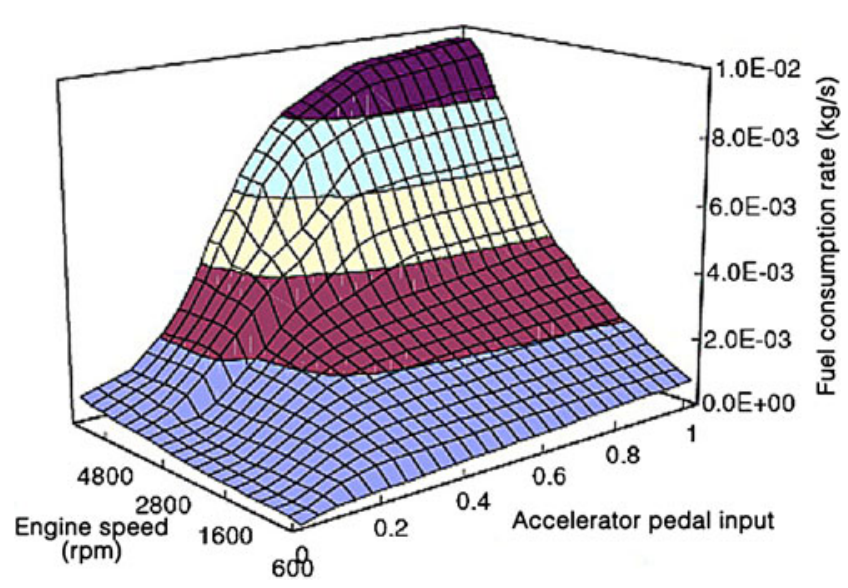

Fig. 4 Fuel consumption rate map 
Table 2 Subject's attribution

\begin{tabular}{|c|c|c|c|}
\hline ID & Age & Driving experience & Driving frequency \\
\hline $\mathrm{A}$ & 23 & $\begin{array}{l}4 \text { years } \\
10 \text { months }\end{array}$ & 1-2 times per week \\
\hline $\mathrm{B}$ & 22 & $\begin{array}{l}2 \text { years } \\
2 \text { months }\end{array}$ & Once in every 2 months \\
\hline $\mathrm{C}$ & 24 & $\begin{array}{l}2 \text { years } \\
11 \text { months }\end{array}$ & $1-2$ times per month \\
\hline $\mathrm{D}$ & 22 & $\begin{array}{l}2 \text { years } \\
11 \text { months }\end{array}$ & 1-2 times per week \\
\hline $\mathrm{E}$ & 22 & $\begin{array}{l}4 \text { years } \\
1 \text { month }\end{array}$ & $1-2$ times per month \\
\hline
\end{tabular}

speed increases However, it is rare to accelerate with full force, with the exception in some particular circumstances, for example, when merging onto an expressway or driving up a steep slope. The area with the accelerator pedal input about 0.2 to 0.6 , called partial throttle area, can be the area where both of the accelerator pedal input and the engine speed become very influential. In particular, an engine speed exceeding 3,600 rpm will tend to sharply increase the fuel consumption amount. In this study, the instantaneous fuel consumption amount $(\mathrm{kg} / \mathrm{s})$ is calculated using the accelerator pedal input and the engine speed obtained with a DS.

Though various models are advocated as fuel consumption amount estimation models, the model in this study was chosen because it could provide the driving behavior of drivers and vehicle control data of the DS based on the behavior, enabling the calculation of the fuel consumption amount using the accelerator pedal input and the engine speed (Fig. 4).

\subsection{Summary of Attribution of Subjects and Instructions}

The subjects are five males (age: 22 to 24 years, average age: 22.6 years, standard deviation: 0.8 years). They filled out the questionnaire about their attribution such as age and

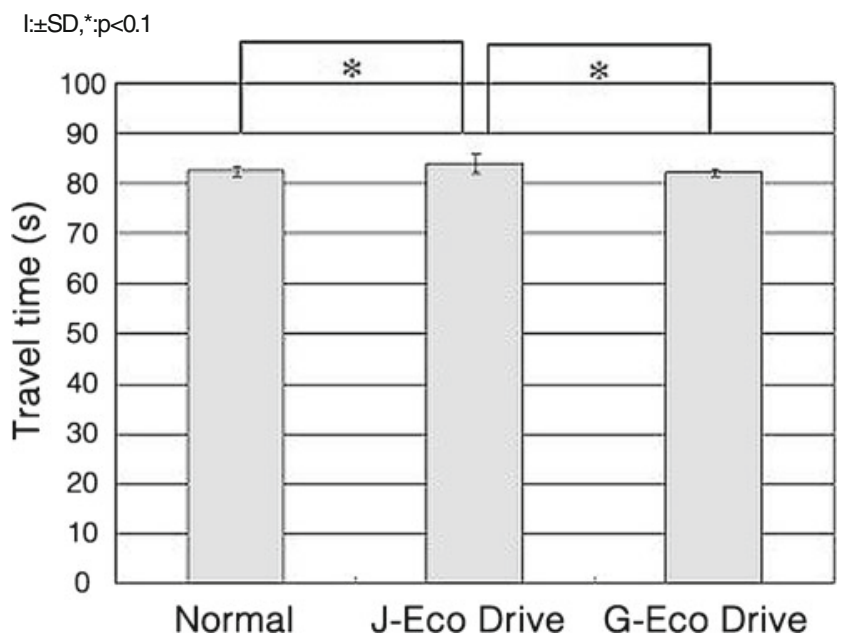

Fig. 5 Comparison of travel time $(n=25)$

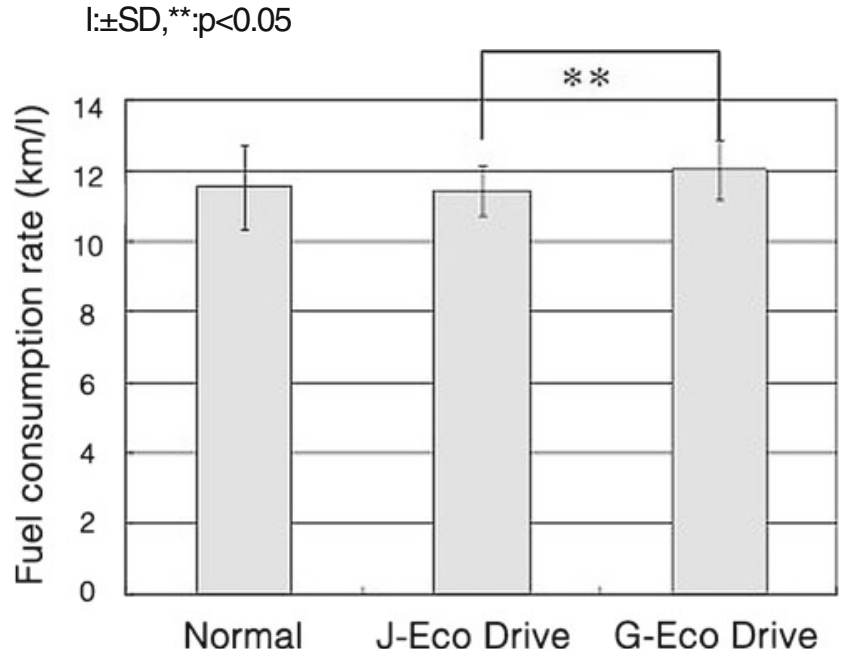

Fig. 6 Comparison of fuel consumption rate of each driving technique $(n=25)$

experience in eco-driving before the experiment. Table 2 summarizes the attributes of each subject who participated in this experiment.

The subjects drove a total of 15 times, 5 times each with normal driving, Japanese eco-driving, German eco-driving in this order. The reason for this order is because it was considered that Japanese and German eco-driving would affect normal driving if the test with normal driving was carried out after those with Japanese and/or German eco-driving. As for the order of Japanese and German eco-driving, it is preferable that the order be randomly set for each subject, in consideration of the order effect. In the study, the order was set to avoid the psychological bias in subjects on safety issues such as getting too close to the preceding vehicle if German eco-driving precedes Japanese one. As only 5 subjects participated in the

$\mathrm{l}: \pm \mathrm{SD},{ }^{* \star *}: \mathrm{p}<0.01$

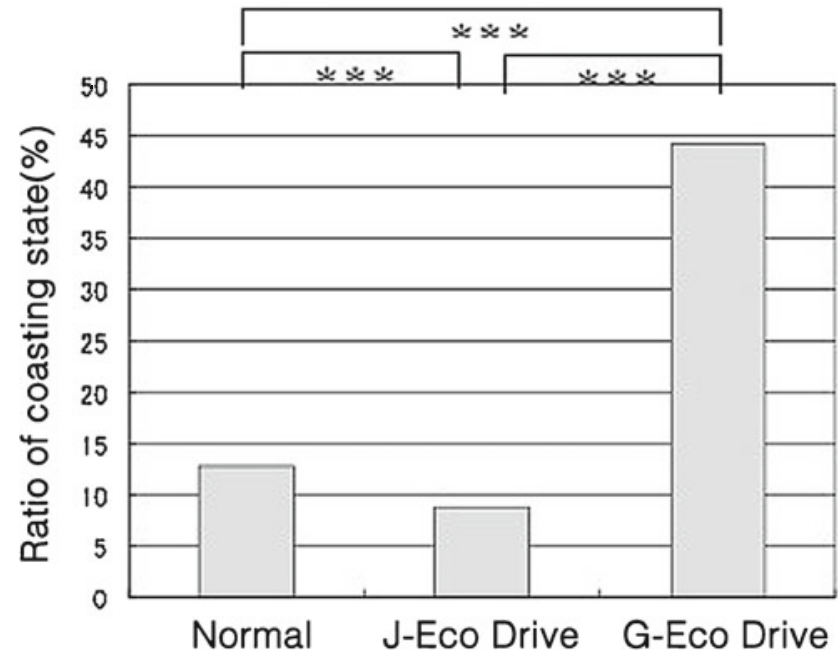

Fig. 7 Comparison of ratio of coasting state of each driving technique $(n=25)$ 
Fig. 8 Example of accelerator pedal input and driving distance (Normal driving)

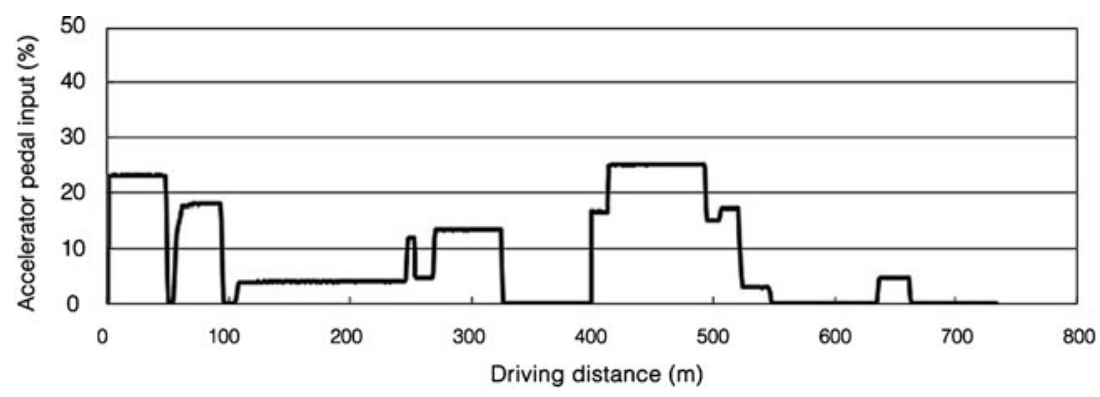

study, the number of driving times was increased so as to obtain more data samples for analysis. As a future challenge, further validation of the experiment with more subjects is necessary. The subjects received instruction on the driving technique and practiced how to drive, before the first test of each driving technique. The instruction is summarized as below.

- Normal driving

Drive in the same way as they do in their daily lives.

- Japanese eco-driving

1) Press on the accelerator gently using creep phenomenon to start moving (approximately $20 \mathrm{~km} /$ $\mathrm{h}$ in $5 \mathrm{~s}$ ).

2) Minimize accelerating and decelerating as much as possible and maintain steady acceleration.

3) Release the accelerator early and actively utilize engine braking.

- German eco-driving

1) Accelerate as fast as possible (but not too quickly) to reach the fuel efficient velocity range (40 to $80 \mathrm{~km} / \mathrm{h}$ ).

2) Release the accelerator after reaching the fuel efficient velocity range and utilize coasting actively.

\section{Experimental Results}

\subsection{Comparison of Travel Time}

In this experiment, the travel time from the starting point to the goal in experimental scenario of Fig. 3 was compared between the normal driving, Japanese eco-driving and German ecodriving. The result is shown in Fig. 5.

When the result went through one-way analysis of variance, the travel time with Japanese eco-driving is longest of all and is longer than that with normal driving by $1.8 \%(1.4 \mathrm{~s})$, and with German eco-driving by $2.1 \%(1.8 \mathrm{~s})(p<0.1)$, as shown in Fig. 5. Why the travel time with Japanese eco-driving is the longest of all is considered to be due to "e-start", one of the characteristics of Japanese eco-driving, which has gentle acceleration. On the other hand, there is no statistically significant difference in the travel time between German eco-driving which accelerates as fast as possible and normal driving. Based on these findings, the comparisons of German eco-driving and Japanese eco-driving with regard to the way of accelerating reveal that "e-start" used in Japanese eco-driving affects travel time more.

\subsection{Comparison of Fuel Consumption Rate}

In this chapter, the fuel consumption rates are compared among each of the driving techniques. They are calculated using the fuel consumption rate map, shown in Fig. 4, based on the accelerator pedal input and the engine speed obtained from the DS. Firstly, the results of the fuel consumption rates for each driving technique are shown in Fig. 6.

When the result went through one-way analysis of variance, the fuel consumption rate with German eco-driving was $4.1 \%$ $(0.48 \mathrm{~km} / \mathrm{l})$ higher than that with normal driving, and that of Japanese eco-driving was $0.87 \%(0.1 \mathrm{~km} / \mathrm{l})$ lower than that of normal driving, as shown in Fig. 6. However, no statistically significant differences were observed in these results.
Fig. 9 Example of accelerator pedal input and driving distance (Japanese eco-driving)

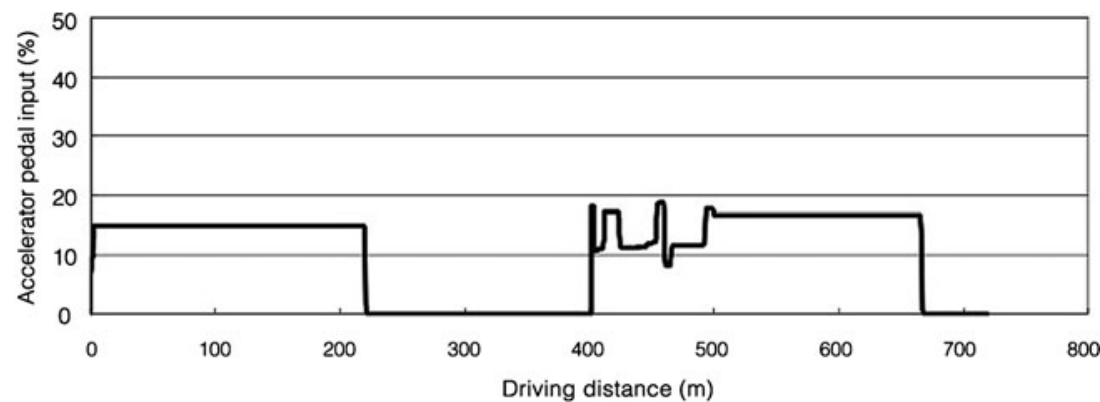


Fig. 10 Example of accelerator pedal input and driving distance (German eco-driving)

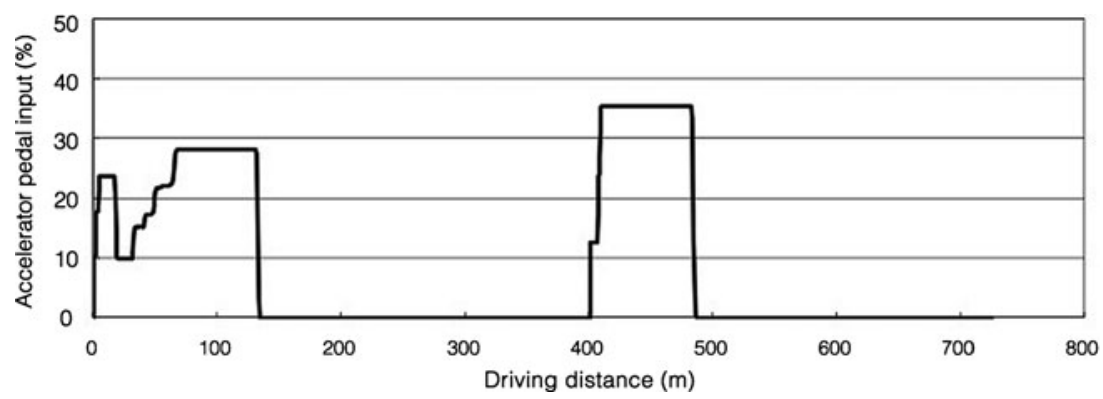

It is shown that the fuel consumption rate with German eco-driving is $5.1 \%(0.56 \mathrm{~km} / \mathrm{l})$ higher than that of Japanese eco-driving $(p<0.05)$.

In general, it is said that driving with Japanese eco-driving would reduce the fuel consumption rate compared to normal driving. However, the results of this experiment do not indicate that Japanese eco-driving, which minimizes accelerating and decelerating, will reduce the fuel consumption rate when the intervals between intersections are short. Next, we define the state with 1) no accelerator pedal input nor brake pedal input and 2) a negative acceleration as the coasting state. The ratio of coasting state, which is the proportion of the driving time in the coasting state to the total travel time, is calculated. The result is shown in Fig. 7. Figure 7 shows that the ratio of coasting state with German eco-driving is by far the highest, and that with Japanese eco-driving is the lowest $(p<0.01)$.

Additionally, as an example of driving distance and accelerator pedal input for each of normal driving, Japanese ecodriving and German eco-driving in the scenario for this experiment, the driving data of the third test by Subject A is shown in Figs. 8, 9 and 10.

As shown in Fig. 9, with Japanese eco-driving, the duration the accelerator is pressed is long even though the accelerator pedal input is small because Japanese eco-driving utilizes "estart", which made its ratio in the coasting state small. This can

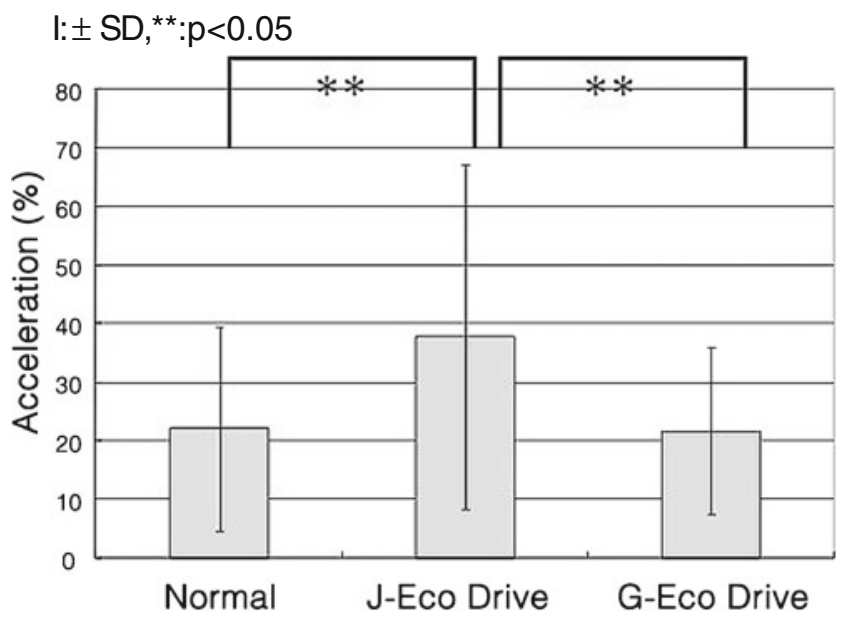

Fig. 11 Headway distance of each driving technique be the reason why the fuel consumption rate with Japanese eco-driving was worse than that with German eco-driving.

On the other hand, as shown in Fig. 10, the fuel consumption rate with German eco-driving right after the start is higher because the accelerator pedal input is high at the start. It is considered that its fuel consumption rate is better than those of the other driving techniques because when it goes into the coasting state, it requires little fuel consumption after that.

Thus, this study suggested that Japanese eco-driving would not always have an effect to reduce the fuel consumption rate compared to normal driving if a vehicle starts moving and stops within a short distance, although many previous studies have reported that as to the effectiveness of eco-driving, Japanese eco-driving improves the fuel consumption rate.

In addition, we quantified the fuel consumption rates in driving a short distance with Japanese eco-driving and German eco-driving, which was regarded as a problem in the study by Hiraoka et al. [9]. As a result, we could suggest the possibility to improve fuel consumption rates with German eco-driving in such a case where the driving distance from starting to stopping is short. Further validation should be necessary in the future, on the influence of differences in traffic situations such as distance between traffic signals, traffic volume, mix rate of large-sized vehicles and so on.

\subsection{Comparison of Driving Techniques and Headway Distance}

Figure 11 shows the result of one-way analysis of variance on headway distances with the preceding vehicle for normal driving, Japanese and German eco-driving. Comparison of each driving technique based on this Figure shows the trend that Japanese eco-driving created longer headway distance than normal driving and German eco-driving.

This is also considered to be caused by the difference between Japanese eco-driving with gentle acceleration and German eco-driving with acceleration as quickly as possible to the fuel efficient velocity range.

As shown in Fig. 11, comparison of each driving technique with regard to the headway distance indicates that the distance with Japanese eco-driving is twice as long as those of normal 
driving and German eco-driving. In addition, a comparison of each driving technique shows that the headway distance with Japanese eco-driving varies far more widely than those with the others.

\section{Conclusion}

In this study, the fuel consumption rates with normal driving, Japanese eco-driving and German eco-driving on a straight open road were compared quantitatively using TS/DS integration, which enables the performance of experiments repeatedly under the same conditions. Though the experiment was only performed on a 700-m open road, the result indicated that German eco-driving reduced the fuel consumption rate by approximately $4 \%$ compared to Japanese eco-driving.

In addition, there were no statistically significant differences between normal driving and Japanese eco-driving or German eco-driving. This result suggests that Japanese ecodriving would not be always helpful to reduce the fuel consumption if the distance from the start to stopping is shortened due to a traffic signal, or other reasons.

Furthermore, the relationship between driving manner and headway distance were shown, focusing on the difference in the driving behavior for each style of eco-driving. The result suggested that Japanese eco-driving creates headway distance about twice as long as that by normal driving. It should be noted that this result is not exactly common, as these figures were obtained under the condition that the vehicles should stop two times at traffic signals during their 700-m drive.

In the future, we intend to study quantitatively the effect of eco-driving on the whole traffic flow in the case of high volume traffic. In addition, we intend to study in detail the difference between those subjects who drive with eco-driving techniques routinely and those who don't, by performing an experiment with an increased number of subjects. Moreover, we plan to analyze the changes in fuel consumption amount depending on traffic situations, distance between traffic signals, instructions on eco-driving and so on. Furthermore, we plan to try a new condition of experiment where a DS controlled vehicle is driven while reading the movement of the preceding vehicle in order to drive in the most fuel efficient manner.

Open Access This article is distributed under the terms of the Creative Commons Attribution License which permits any use, distribution, and reproduction in any medium, provided the original author(s) and the source are credited.

\section{References}

1. The Eco-Drive Promotion Liaison Committee: 10 tips for fuelconserving Eco Driving. (2005)
2. Ford-Werke GmbH: Ford Eco-Driving Kompakt, http://www.fordeco-driving.de/

3. Maji, H., Kasuga, N., Ishi, T., Daisho, Y.: Effects of eco-drive activity on improvement in fuel economy and reduction in traffic accidents. Proc. JSAE 38(3), 99-104 (2007)

4. Saito, A., Takada, H.: The relationship between eco-driving patterns of light duty freight vehicles and the improvement of fuel economy in real traffic conditions. Proceedings of JSAE before lecture presentation, No.99-08. pp. 27-30 (2008)

5. Miyasaka, T., Taniguchi, M., Sanbuichi, H.:Potentiality of effects by driving operation for fuel conservation to automatic transmission car. Proceedings of JSAE before lecture presentation, No.80-05. pp.13$16(2005)$

6. Beusen, B., Denys, T.: Experiences using an onboard logging device with CAN-interface, GPS, GPRS, and Wi-Fi for surveying long term driving behavior. Proceedings of 15 th World Congress on Intelligent Transport Systems, CD-ROM. (2008)

7. Matsumoto, S., Kobayashi, I., Nakamura, A., Kawashima, H.: Economic evaluation of influence on traffic flow by eco-driving. Annual report of JSTE, Japan Society of Transportation Economics. pp. 169178 (2007)

8. Kato, H., Kobayashi, S.: Factors contributing to improved fuel economy in eco-drive. J. JSAE 62(11), 79-84 (2008)

9. Hiraoka, T., Terakado, Y., Matsumoto, S., Yamabe, S.:Quantitative evaluation of eco-driving on fuel consumption based on driving simulator experiments. Proceedings of 7 th World Congress on Intelligent Transport Systems. pp. 163-168 (2008)

10. Babazono, K.: Introduction of microsimulation environment tool, AIMSUN NG. IPSJ SIG Technical Reports ITS 2005(61), 13-20 (2005)

11. Munehiro, Y., Yamazaki I., Daimon T., Arizumi M.: A countermeasure for crossing collisions based on analysis of human error using driving simulator. Infrastruct. Plan. Manag. JSCE/Proc. 34 (2006), CD-ROM

12. Nakamura, A., Matsumoto, S., Todoroki, T.: Measuring external costs of on-street parking near the bus-stop: the case of Chiba. Annual report of JSTE, Japan Society of Transportation Economics, pp.159-168 (2008)

13. Matsumoto, S., Kumagai, Y., Kawashima, H.: A study on the traffic signal strategy in city traffic in consideration of streetcar. Infrastruct. Plan. Manag. JSCE/Proc 21(3), 677-685 (2004)

14. Matsumoto, S., Tozawa, T., Hiraoka, T., Yamabe, S., Kawashima, H.: A fundamental study on the effect of eco-driving on following vehicles. Infrastruct. Plan. Manag. Proc. D3 67(5), I 1023-I_1028 (2012)

15. Hiraoka, T., Terakado, Y., Matsumoto, S., Yamabe, S.: Effect of ecodriving instruction and fuel consumption meter on fuel consumption reduction. Hum. Interf. Soc. J. 12(1), 71-78 (2011)

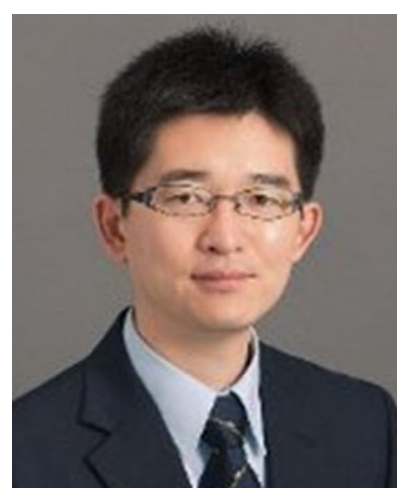

Shuichi Matsumoto Ph.D., Lecturer. He is a specialist in ITS, regional transportation planning, and Traffic Simulation. 


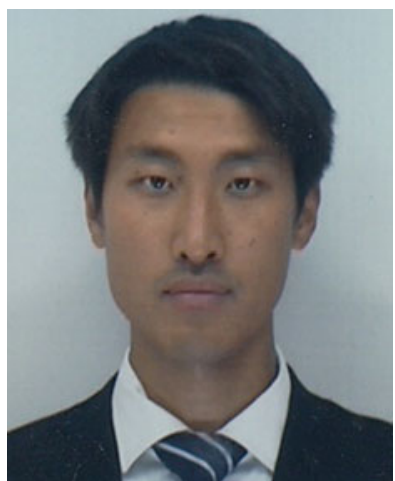

Taehwi Park ME., Student of Asahikawa Medical University. He conducted research on ITS in his master course at KEIO University.

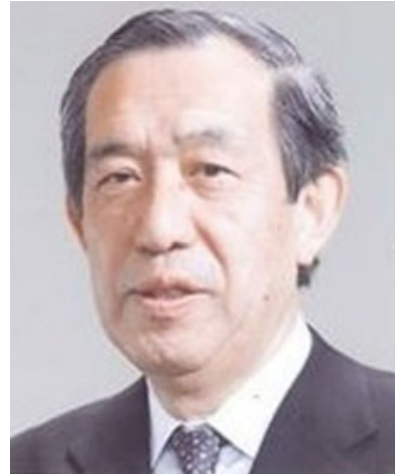

Hironao Kawashima Ph.D.

Emeritus Professor. He is involved in international project such as the standardization of ITS in ISO/TC204. 